\title{
Motivation for everyday social participation in cognitively able individuals with autism spectrum disorder
}

This article was published in the following Dove Press journal:

Neuropsychiatric Disease and Treatment

15 October 2015

Number of times this article has been viewed

\author{
Yu-Wei Chen' \\ Anita C Bundy' \\ Reinie Cordier ${ }^{2}$ \\ Yi-Ling Chien ${ }^{3}$ \\ Stewart L Einfeld ${ }^{1,4}$ \\ 'Faculty of Health Sciences, The \\ University of Sydney, Sydney, NSW \\ Australia; ${ }^{2} \mathrm{School}$ of Occupational \\ Therapy and Social Work, Faculty of \\ Health Sciences, Curtin University, \\ Perth, WA, Australia; ${ }^{3}$ Department of \\ Psychiatry, National Taiwan University \\ Hospital and College of Medicine, \\ Taipei, Taiwan; ${ }^{4}$ Brain and Mind \\ Research Institute, The University of \\ Sydney, Sydney, NSW, Australia
}

Objective: The purpose of the present study was to examine motivation for the contextual nature of motivations for social participation in cognitively able adolescents and adults with autism spectrum disorder, using self-determination theory as a theoretical framework.

Methods: Fourteen Australians and 16 Taiwanese (aged 16-45 years) with Asperger's syndrome and high functioning autism were asked to carry a device which prompted them seven times/day for 7 days, to record what they were doing, with whom, perceived difficulty and social reciprocity, and the reasons for engaging in a situation, which were then coded into degree of self-determination. Results: Multilevel analyses showed that participants were more likely to be self-determined while engaging in "solitary/parallel leisure" and "social activities" than in other types of activities. Interactions with "family members" and "casual/intimate friends" were also positively associated with self-determined motivation. Further, participants were more likely to perceive higher levels of being listened to during interaction with casual/intimate friends than in interaction with other people. Global social anxiety served as a moderator for their perceptions of difficulty and social reciprocity during social engagement.

Conclusion: The findings highlight the context-dependent motivations for social engagement of cognitively able individuals with autism spectrum disorder.

Keywords: autism, real-life experience, social motivation, social interaction, ecological momentary assessment

\section{Introduction}

Cognitively able adolescents and adults with a diagnosis of autism spectrum disorder (ASD), such as those once diagnosed with Asperger's syndrome (AS) or high functioning autism, commonly have restricted social participation as a result of social and communication deficits. ${ }^{1-4}$ They frequently report social isolation and negative experiences in social situations, which may influence their motivation for social engagement.

Whether individuals with ASD wish to engage socially (ie, possess social motivation) is controversial. Theory and research examining this question is inconclusive and the findings are at odds. The term "autism" is drawn from the Greek word, "autos", meaning "self". The name was first applied to children who were socially isolated, seemingly by choice. Thus, the popular belief that individuals with ASD lack the motivation to engage socially. Recently, Chevallier et al proposed a social motivation theory of autism, describing it as an extreme case of diminished social motivation. ${ }^{5}$ Other researchers studying social motivation concluded that children with ASD display less desire for interaction than typically developing peers, ${ }^{6}$ a finding explicitly and directly gleaned from asking participants to view pictures of people taken from the side view and indicate whether they wanted to interact with those individuals.
Correspondence: Yu-Wei Chen

Faculty of Health Sciences, The University of Sydney, 75 East Street, Lidcombe, NSW 214I, Australia

Tel +6I 293519798

Email yu-wei.chen@sydney.edu.au 
The results of other studies refute the poor social motivation hypothesis. For example, Deckers et al asked children with ASD to indicate whether they would like to get acquainted with individuals presented in profile pictures of faces. ${ }^{6}$ If they wanted to know a person, they pulled on a joystick and turned the photo toward them. If they did not want to meet the person, they pushed on the joystick which turned the picture away (ie, Face Turn Approach-Avoidance Task). ${ }^{7}$ Unlike asking them explicitly, using this implicit approach, Deckers et al found that children with ASD were inclined to express a desire to approach others. Other researchers ${ }^{8,9}$ have used electroencephalography with cognitively able children with ASD, finding greater left than right anterior cortical activity while at rest, a pattern associated with a disposition to approach socially. ${ }^{10}$

A third hypothesis is that social motivation in individuals with ASD is context dependent. That is, individuals are motivated to engage socially in specific contexts and not in others. For example, using experience sampling methodology (ESM), Hintzen et al found that cognitively able adults with ASD chose to spend more time with familiar people than did adults without ASD. ${ }^{11}$ In addition, we found that cognitively able adolescents and adults with ASD reported enjoying everyday social situations when they were conversing with friends compared with other people or being alone (Chen et al, unpublished data, 2015).

Self-determination theory (SDT), ${ }^{12-14}$ which focuses on how social contexts affect engagement, may help understand the contextual nature of motivations for social interaction in people with ASD. Instead of treating motivation as a unitary construct, SDT addresses the orientation/type of motivation which concerns the reasons or goals that give rise to an action. ${ }^{14}$ According to SDT, motivations can be self-determined in situations that individuals find compelling (ie, intrinsically motivated) or that they think are good for them (ie, identified regulation). In contrast, individuals sometimes perform behaviors to satisfy external demands (ie, external regulation), or to avoid guilt or attain recognition (ie, introjected regulation); both are extrinsically motivated. However, amotivated behaviors occur in situations where an individual lacks a reason for or an intention to act.

SDT suggests that orientation of motivation can be predicted by the degree to which an action satisfies basic psychological needs. Deci and Ryan described three basic psychological needs inherent to all human beings: ${ }^{12}$ autonomy, competence, and relatedness. Autonomy comprises feelings of volition and self-ownership. Competence refers to the experience of effectance and mastery. Relatedness is the need to feel connected and experience reciprocal care and love.

Human needs play a mediating role between the actions of individuals and the social context. ${ }^{12-14}$ Deci and Ryan suggested that participation in a supportive social environment is crucial to satisfaction of psychological needs; which, in turn, facilitates self-determined behaviors and positive experiences. Our previous findings that cognitively able adolescents and young adults with ASD enjoyed social interactions with certain contexts suggests that those interactions met basic needs. In contrast, Whitehouse et al found that adolescents with AS have little intrinsic motivation for establishing friendships, probably because their needs are not met. ${ }^{15}$

The lack of clarity around the motivation for social participation of adolescents and adults with ASD may, in part, reflect differences in methodology. While we have used ESM ${ }^{16,17}$ to explore social experiences in everyday contexts, most previous researchers have used retrospective interview or global self-rating scales. For example, Whitehouse et $\mathrm{al}^{15}$ used the Friendship Motivation Questionnaire, ${ }^{18}$ which required participants to indicate how true statements were of them. This task is highly cognitive, requiring aggregation of experiences over time. ${ }^{19}$ Retrospective responses are easily contaminated by memory bias $^{20}$ or by the emotional states elicited by reflective questioning. ${ }^{19}$ More importantly, retrospective and one-time reporting are divorced from real life contexts and experiences of social participation. Thus, the low motivation for social engagement identified by Whitehouse et $\mathrm{al}^{15}$ may not truly reflect their social desires in everyday life.

ESM is an ecological momentary assessment used to identify dynamic relationships between subjective experiences and everyday contexts. ${ }^{19}$ ESM allows participants to report their actions, momentary thoughts, and feelings in real time, across natural settings and over a period of time. This method enables to identify fluctuations in perceptions about everyday experiences within a person. ${ }^{21}$ As such, it is suited to capturing the variability inherent to the ASD population. Unlike single-case studies, data collected with ESM can be aggregated and analyzed at within- and between-person levels simultaneously. ${ }^{21}$ In addition, compared with retrospective approaches, data collected through ESM have greater ecological validity and are less subject to recall or social appropriateness bias. ${ }^{16,19}$ Further, ESM survey questions are short, straightforward, and address only the immediate context, which involves less cognitive demand than retrospective methods. Recent research has established the validity and usability of ESM with the ASD population. ${ }^{11,22-26}$

The purpose of the present study was to examine motivation for social participation in everyday contexts among cognitively able adolescents and adults with ASD. We used SDT as a theoretical framework and ESM as a methodology. To examine the extent to which the basic needs of competence and relatedness were met in everyday social experiences, we 
investigated perceptions of difficulty and social reciprocity. Given the heterogeneity of people with ASD and our previous findings (Chen et al, unpublished data, 2015), we examined severity of ASD symptomology and global social anxiety as moderators of motivation for and perceptions of everyday participation. In addition, because we had found that Australian females with ASD are more socially active than Australian males and Taiwanese people (Chen et al, unpublished data, 2015), we also examined whether participant group (Australian females vs other people) served as a moderator.

\section{Methods}

The study had approval from the University of Sydney Human Research Ethics Committee, the Autism Spectrum Australia Research Approval Committee, and the Research Ethics Committee of National Taiwan University Hospital (NTUH). All participants provided written consent, and parents provided additional consent for participants younger than 18 . Because the study began prior to release of the Diagnostic and Statistical Manual of Mental Disorders (DSM) 5th edition, ${ }^{27}$ we used DSM-IV criteria for ASD diagnosis.

\section{Participants}

Thirty-two individuals with AS or high functioning autism agreed to participate: 14 Australians (four males) were recruited via research flyers circulated around Australia and 18 Taiwanese (14 males) were referred by psychiatrists employed at NTUH. All individuals met the following inclusion criteria: 1) a formal diagnosis from a psychiatrist or psychologist using the DSM-IV criteria; ${ }^{3} 2$ ) aged between 16 and 45 years, and 3 ) having sufficient reading comprehension to understand the surveys. Reading comprehension of Australian participants was confirmed by standard scores of $\geq 85$ on the Reading Comprehension Subtest of Woodcock Reading Mastery Test-3rd edition..$^{28}$ Because there are no equivalent reading assessments for Taiwanese adults, the reading comprehension of Taiwanese participants was confirmed by a verbal intelligence quotient $\geq 70$ on the Wechsler Adult Intelligence Scale-IV.$^{29}$ No participants had a diagnosis of intellectual disability, neurological or other developmental disorders (eg, cerebral palsy).

In order for their data to be included, participants had to have completed at least 17 of 49 surveys ( $>33 \%$ ) in accordance with suggestions from previous researchers. ${ }^{30}$ Data from two Taiwanese males were excluded from the final sample. One discontinued participation after encountering technical issues with the iOS device. The second completed only 15 surveys in 7 days; the minimum requirement was 17 surveys (see Procedure). Thus, the final sample included data from 14 Australians (four males; aged 16-43 years [mean $=24.8$, standard deviation $\{\mathrm{SD}\}=9.0]$ ) and 16 Taiwanese ( 12 males; aged $19-45$ years $[$ mean $=27.8, \mathrm{SD}=6.3]$ ).

In the final sample, the main diagnosis was AS ( $\mathrm{n}=12$ [86\%] in the Australian group and $n=13$ [81\%] in the Taiwanese group; Table 1). Half of the Australian participants

Table I Characteristics of individuals with autism spectrum disorder (ASD)

\begin{tabular}{|c|c|c|}
\hline Characteristics $^{a}$ & $\begin{array}{l}\text { Australia } \\
(n=\mid 4)\end{array}$ & $\begin{array}{l}\text { Taiwan } \\
(n=16)\end{array}$ \\
\hline \multicolumn{3}{|l|}{ Sex } \\
\hline Male & $4(28.6)$ & $12(75.0)$ \\
\hline Female & $10(71.4)$ & $4(25.0)$ \\
\hline \multicolumn{3}{|l|}{ ASD diagnosis } \\
\hline HFA & $2(14.3)$ & $3(18.8)$ \\
\hline AS & $12(85.7)$ & $13(81.3)$ \\
\hline \multicolumn{3}{|l|}{ Comorbid diagnoses } \\
\hline ADHD & I (7.I) & $2(12.5)$ \\
\hline Depression & I (7.I) & 0 \\
\hline Anxiety & I (7.I) & 0 \\
\hline OCD & 0 & $2(12.5)$ \\
\hline Depression and anxiety & $3(2 \mid .4)$ & 0 \\
\hline Depression and anxiety and $O C D$ & I (7.I) & 0 \\
\hline Age in years & $24.8(9.0)$ & $27.8(6.3)$ \\
\hline Total standard scores of SRS & $77.7(6.5)$ & $70.6(8.7)$ \\
\hline Total raw scores of SIAS & $46.0(14.2)$ & $44.1(17.3)$ \\
\hline $\begin{array}{l}\text { Reading comprehension abilities } \\
\text { (standard scores) }^{\mathrm{b}}\end{array}$ & $107.3(9.4)$ & $106.2(13.1)$ \\
\hline \multicolumn{3}{|l|}{ Living status } \\
\hline Alone & $2(14.3)$ & $\mathrm{I}(6.3)$ \\
\hline With partner/children & $3(21.4)$ & 0 \\
\hline With parents/siblings & $6(42.9)$ & $15(93.8)$ \\
\hline With others & $3(2 \mid .4)$ & 0 \\
\hline \multicolumn{3}{|l|}{ Relationship status } \\
\hline Single & $9(64.3)$ & $12(75.0)$ \\
\hline Boyfriend/girlfriend & I (7.I) & $3(18.8)$ \\
\hline Partner/married & $3(2 \mid .4)$ & 0 \\
\hline Separated/divorced & 0 & $\mathrm{I}(6.3)$ \\
\hline Other & I (7.I) & 0 \\
\hline \multicolumn{3}{|l|}{ Completed education level } \\
\hline High school & $4(28.6)$ & $4(25.0)$ \\
\hline Certificate & $5(35.7)$ & 0 \\
\hline Diploma & $2(14.3)$ & 0 \\
\hline Associate's degree & 0 & $\mathrm{I}(6.3)$ \\
\hline Bachelor's degree & I (7.I) & $9(56.3)$ \\
\hline Master's degree & $2(14.3)$ & $2(12.5)$ \\
\hline \multicolumn{3}{|l|}{ Current employment/education status } \\
\hline Student & $7(50.0)$ & $4(25.0)$ \\
\hline Unemployed & I (7.I) & $7(43.8)$ \\
\hline Part-time & $2(14.3)$ & I (6.3) \\
\hline Full-time & $3(21.4)$ & $4(25.0)$ \\
\hline Volunteer work & I (7.I) & 0 \\
\hline
\end{tabular}

Notes: a Count (\%) for categorical data, mean (standard deviation) for continuous data. 'Measured by Woodcock Reading Mastery Test-3rd Edition for Australian participants and a verbal IQ for Taiwanese sample.

Abbreviations: HFA, high-functioning autism; AS, Asperger's syndrome; ADHD, attention deficit/hyperactivity disorder; OCD, obsessive-compulsive disorder; SRS, Socia Responsiveness Scale; SIAS, Social Interaction Anxiety Scale; IQ, intelligence quotient. 
and a quarter of the Taiwanese participants had concomitant mental health diagnoses (eg, attention deficit/hyperactivity disorder, depression, anxiety, obsessive-compulsive disorder). Regarding current education and employment status, seven (50\%) Australians and four (25\%) Taiwanese were still students. One (7\%) Australian and seven (44\%) Taiwanese were unemployed.

\section{ESM}

We developed an ESM survey to explore what participants were doing (everyday activities, Figure 1 for options) and who they were communicating with (social interaction conditions, Figure 2 for options). Each time they were signaled, participants chose the main activity in which they were engaged and as many social partners as were relevant. They indicated why they were doing the activity (from a list) and their experiences of: a) difficulty of activity engagement, and b) social reciprocity during interactions. Social reciprocity included questions about being listened to (do you think they were really listening to what you had to say?) and caring about others (did you care about what they were doing/ saying?). Participants responded "yes" or "no" to perceived difficulty and from " 0 " (not at all) to " 10 " (very much) for perceived social reciprocity. The ESM survey was loaded to the Participation in Everyday Life Survey Application (PIEL App), an ESM platform designed for iOS devices. ${ }^{31}$ The PIEL App prompted participants to complete the ESM surveys, time stamped the responses, and stored the data.

\section{Measures of ASD severity and global social anxiety}

The Social Responsiveness Scale - Second Edition (SRS-2) ${ }^{32}$ was used to evaluate the severity of ASD symptoms. In Taiwan, the Chinese version of SRS ${ }^{33}$ was used. The SRS-2 is a parent/teacher-report or self-report questionnaire for individuals 2.5 years or older. In this study, participants who were aged 19 years and above completed the "selfreport version". Parents of younger participants under 19 completed the "school-age version". The SRS-2 comprises 65 items organized into five subscales: social awareness, social cognition, social communication, social motivation, and restricted interests and repetitive behaviors. Items are rated on a 4-point Likert scale from 0 (not true), to 3 (almost always true). Total standard scores of 60 or higher are clinically significant and indicate deficiencies in social reciprocal behavior that may interfere with everyday social interactions. The SRS-2 has evidence of sound psychometric properties when used with adults. ${ }^{32,34}$
To evaluate the severity of global social anxiety in Australian and Taiwanese participants, the Social Interaction Anxiety Scale (SIAS) ${ }^{35}$ and the Chinese version of the SIAS $^{36}$ were used. The 20 -item self-report scale measures experiences in social situations associated with social anxiety according to DSM-IV criteria. ${ }^{3}$ Participants rated the items using a 5-point scale $(0=$ "not at all characteristic of me" to $4=$ "extremely characteristic of me"). Higher total scores indicate greater levels of social anxiety. The SIAS and Chinese version of the SIAS have good evidence of reliability and validity across clinical and community populations. ${ }^{35,36}$

\section{Procedure}

We provided participants with an iPod Touch or delivered the PIEL App to their iOS device (ie, iPod Touch or iPhone). We conducted a 30- to 60-minute individual training session with each participant on the use of the PIEL App and the iOS device. The training was held at a university campus, outpatient clinic of the hospital or a quiet public place (eg, a library). During the training, participants also completed the SIAS and the SRS-2. Parents of participants under 19 received the school-age version of SRS-2 by mail. Australian participants took the Woodcock Reading Mastery Test-3rd edition to ensure reading comprehension ability.

Following training, participants carried the device for 7 consecutive days. The device prompted participants seven times each day at random intervals to respond to the same ESM survey. Each participant determined the available hours for sampling time by identifying their waking hours. They were instructed to answer as many surveys as possible but to ignore signals that occurred at inconvenient times (eg, when bathing). The survey became dormant if participants did not respond to a prompt within 2 minutes. Participants were encouraged to contact the first author directly if they required assistance.

\section{Data analysis}

We plotted the data for descriptive analysis. We coded activities into five types: "non-activity", "productivity", "solitary/ parallel leisure", "social activities", and "self-care" (Figure 1 for types). We coded reasons for engaging in activities into five levels based on degree of self-determination drawn from SDT: ${ }^{12}$ a) intrinsic motivation (I like it), b) three levels of extrinsic motivation: identified regulation (I am doing it for my own good); introjected regulation (I want people to like me; I want to look occupied), and external regulation (I have to), and c) amotivation (It's just a habit; nothing else to do). For each participant, we calculated the proportion of each motivation associated with each activity and interaction 


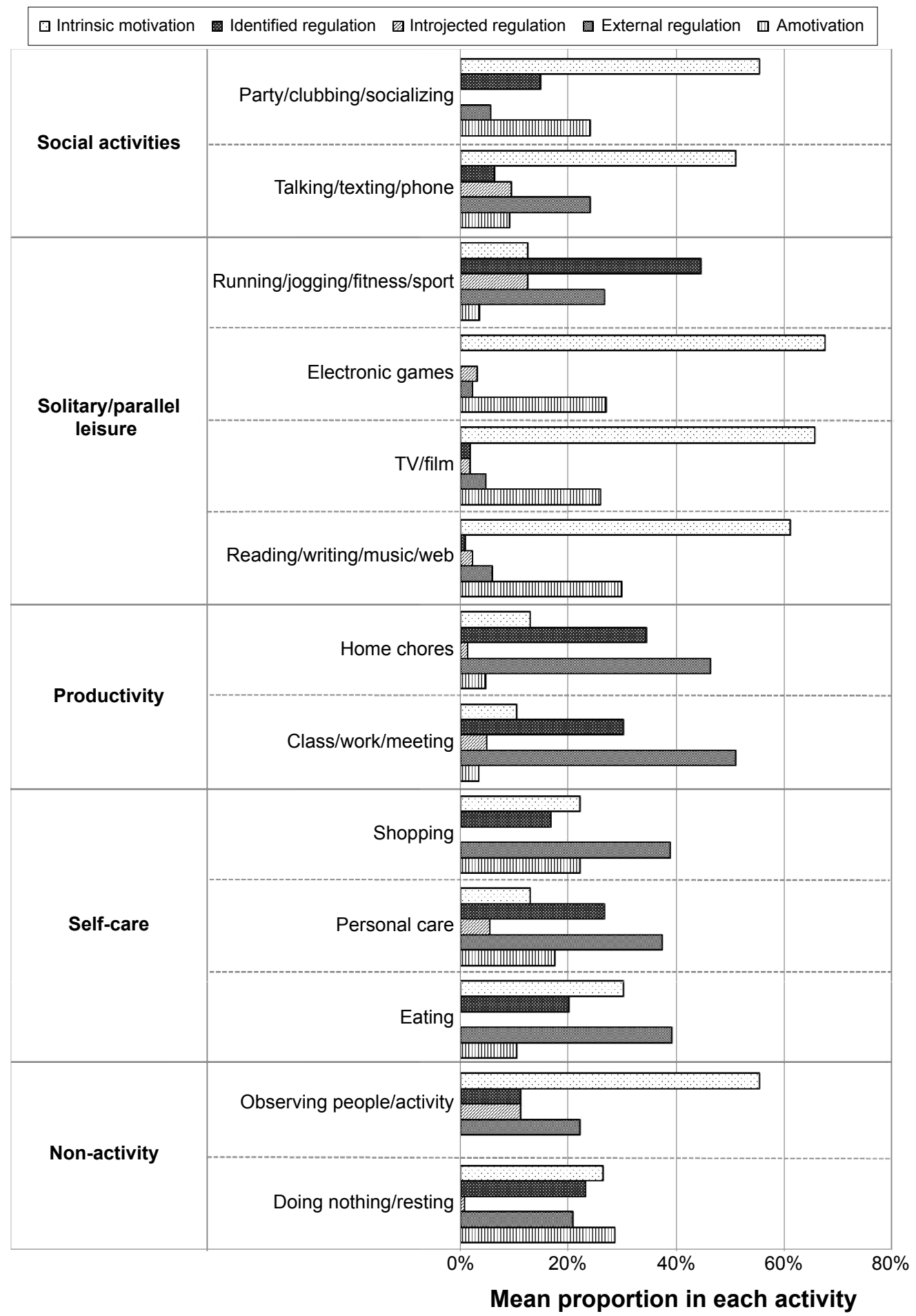

Figure I Motivation for engagement in everyday activities.

with different people. We also calculated the proportion of perceived difficulty and overall means of social reciprocity associated with each activity and interaction, respectively. Prior to calculating overall means, we centered each participant's ratings at his or her mean to account for individual differences.
ESM data have a hierarchical structure with multiple surveys (Level 1) nested within data from each participant (Level 2). We performed multilevel analyses to examine how motivation and perceptions were associated with everyday participation. Given that multilevel analysis takes into account the dependency of the surveys from the same 


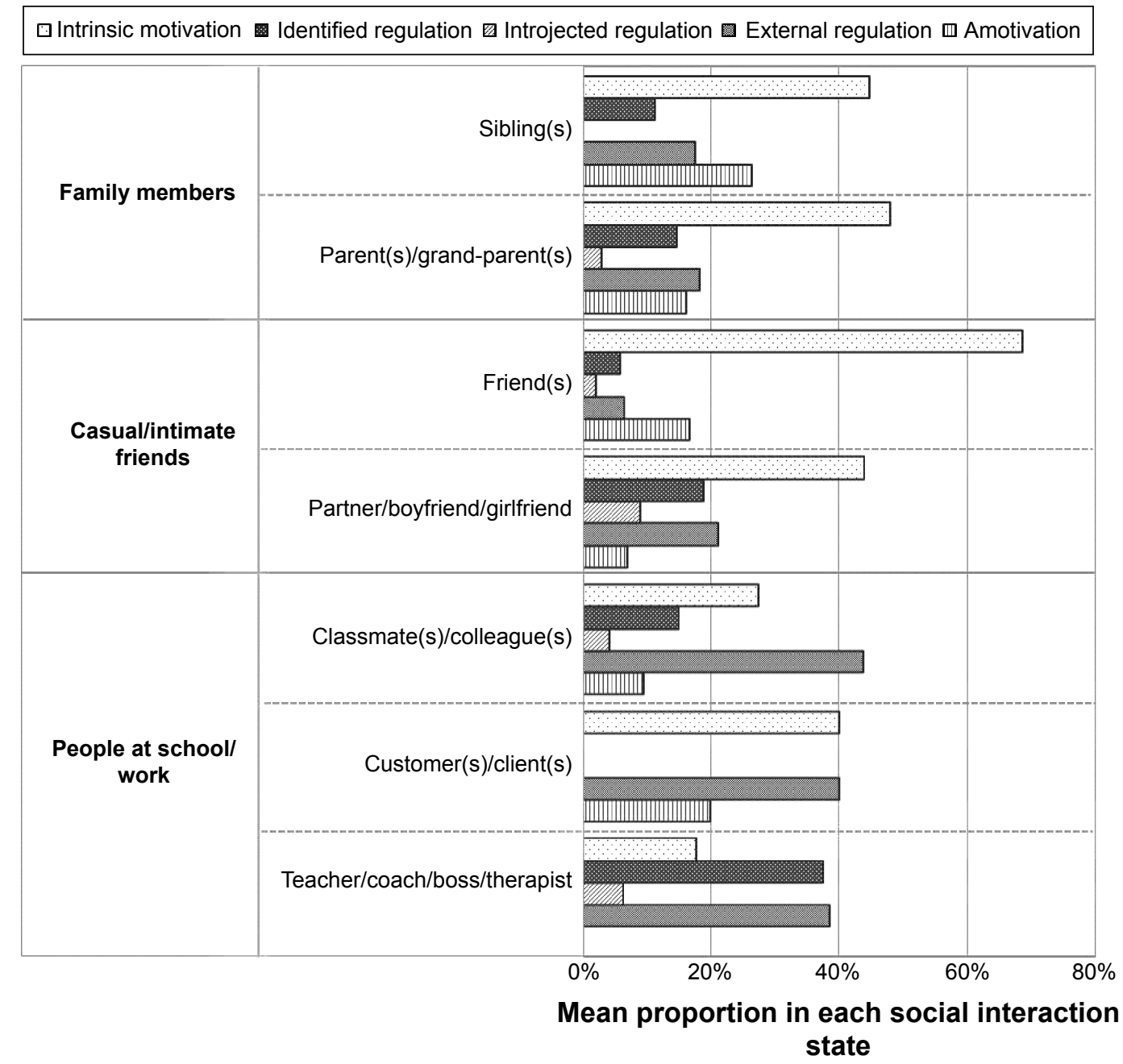

Figure 2 Motivation for interaction with people.

participant, ${ }^{37,38}$ the method is preferred over the conventional ordinary least squares approaches for ESM data. ${ }^{39,40}$ In addition, multilevel analysis allows examination of relationships between variables at different levels and also accounts for potential moderating effects of Level 2 variables on the relationships of Level 1 variables. ${ }^{37,38}$ Previous researchers suggested a minimum Level 2 sample size of 30 to achieve sufficient power. ${ }^{41,42}$

We examined associations between everyday activities and the dependent variables, "degree of self-determination" and "perceived difficulty", in two multilevel logistic analyses. In each analysis, "non-activity", "productivity", "solitary/parallel leisure", and "social activities" were the Level 1 independent variables and "self-care" was the reference. To examine source of motivation as a dependent variable in multilevel logistic analysis, the five motivation levels were coded as "relatively self-determined" (intrinsic motivation, identified regulation) or "relatively externally determined" (introjected regulation, external regulation, amotivation); the "relatively externally determined" was the reference.

To examine perceived social reciprocity, we conducted two multilevel linear analyses with "being listened to" and "caring about others" as continuous dependent variables. Because participants were able to select multiple social partners in a single interaction, we coded each social partner as a binary (yes/no) variable: "no one", "family members", "casual/intimate friends", or "people at school/work". All the four types of social partners were included as Level 1 independent variables in the analysis of motivation. The analyses of perceived social reciprocity included only three independent variables: "family members", "casual/intimate friends", and "people at school/work" because social reciprocity requires the presence of a social partner.

In each multilevel analysis, we simultaneously analyzed individual characteristics as Level 2 independent variables to examine their associations with motivation and perceived social reciprocity. These variables were severity of ASD (ie, total 
standard scores of SRS-2), severity of global social anxiety (ie, total raw scores of SIAS), and participant group (Australian females vs other participants). SRS-2 and SIAS data were grand mean centered for comparisons across participants. ${ }^{37,38}$

To examine potential moderating effects of individual characteristics (severity of ASD, global social anxiety, and participant group), we added the interactions between Level 1 and Level 2 independent variables to the original multilevel analyses. These additional analyses helped identify whether the Level 2 independent variables moderated the relationships between Level 1 independent and dependent variables. To reduce model complexity and maximize stability, we removed cross-level interactions which showed no significant relationships to the dependent variable when establishing the final model. ${ }^{37,38}$

We used Hierarchical Linear and Nonlinear Modeling (HLM 6.08) software ${ }^{43}$ to perform the multilevel analyses. Associations between independent and dependent variables were evaluated through the estimation of the odds ratios (ORs) and corresponding 95\% confidence intervals (CIs) for the multilevel logistic analysis, and a fixed regression coefficient $(\beta)$ and standard errors for the multilevel linear analysis. Significance in cross-level interaction indicates a significant moderating effect of a Level 2 independent variable on the relationship between Level 1 independent and dependent variables.

\section{Results}

Participants completed an average of 38 , of a possible 49 (average response rates: $77.6 \%$ ), ESM surveys ( $\mathrm{SD}=7$, range $=23-49$ ), providing a total of 1,131 surveys. Overall, participants spent the majority of time engaging in activities related to "solitary/parallel leisure" (42.4\%), followed by $25.0 \%$ in "productivity" (ie, home chores and class, work or meeting), and $12.2 \%$ in "non-activity". They engaged infrequently $(10.8 \%)$ in "social activities" and they did not interact with another person most of the time (71.6\%). "Casual friends/an intimate friend" (11.4\%) were the ones they mainly interact with when they engaged in conversation.

Figure 1 shows that participants were most frequently intrinsically motivated to engage in social and solitary/ parallel leisure activities, except running/jogging/fitness/ sport where the behaviors were identified as regulated. Conversely, participants were frequently externally regulated (the least autonomous response) when they engaged in selfcare and productive activities. However, participants seldom perceived everyday activities as difficult. They described "productive activities" as difficult only $16.3 \%$ of the time, "social activities" $15.5 \%$ of the time, and "self-care" $10.5 \%$ of the time.

Figure 2 shows that participants were intrinsically motivated to interact with family members and casual/intimate friends. However, they frequently perceived interaction with people at school/work as externally regulated. In terms of perceived social reciprocity, participants perceived relatively high levels of being listened to while interacting with family members (mean $[\mathrm{M}]=0.313, \mathrm{SD}=1.139)$ and casual/intimate friends $(\mathrm{M}=0.281, \mathrm{SD}=0.753)$ compared with people at school/work $(\mathrm{M}=0.004, \mathrm{SD}=0.804)$. Further, they cared more about family members $(\mathrm{M}=0.345, \mathrm{SD}=0.876)$ and casual/intimate friends $(\mathrm{M}=-0.035, \mathrm{SD}=0.985)$ than people at school/work $(\mathrm{M}=-0.305, \mathrm{SD}=0.736)$.

\section{Relationships of motivation and perception of difficulty with everyday activities}

Table 2 summarizes the results of the multilevel analyses of motivation and perceived difficulty of activities. Participants

Table 2 Multilevel logistic analyses of self-determined motivation and perception of difficulty during the engagement in everyday activities ( $N=30$, number of surveys $=I,|3|)$

\begin{tabular}{|c|c|c|c|c|}
\hline \multirow[t]{2}{*}{ Variables } & \multicolumn{2}{|c|}{ Self-determined motivation } & \multicolumn{2}{|c|}{ Perception of difficulty } \\
\hline & OR $(95 \% \mathrm{Cl})$ & $P$-value & OR $(95 \% \mathrm{CI})$ & P-value \\
\hline \multicolumn{5}{|l|}{ Level I } \\
\hline \multicolumn{5}{|l|}{ Types of activity (vs self-care) } \\
\hline Non-activity & $\mathrm{I} .24(0.67-2.3 \mathrm{I})$ & 0.50 & $0.52(0.16-1.74)$ & 0.29 \\
\hline Productivity & $0.58(0.33-1.04)$ & 0.07 & $2.47(1.01-6.06)$ & $<0.05^{*}$ \\
\hline Solitary/parallel leisure & $4.15(2.41-7.15)$ & $<0.01 * *$ & $0.80(0.32-2.00)$ & 0.62 \\
\hline Social activity & $2.11(1.10-4.08)$ & $<0.05^{*}$ & $2.45(0.93-6.44)$ & 0.07 \\
\hline \multicolumn{5}{|l|}{ Level 2} \\
\hline ASD severity & I.05 (0.95-I.I7) & 0.34 & $1.10(0.97-1.26)$ & 0.15 \\
\hline Severity of global social anxiety & $0.96(0.91-1.01)$ & 0.13 & $1.01(0.95-1.07)$ & 0.75 \\
\hline Australian females (vs others) & $0.56(0.14-2.35)$ & 0.42 & $2.58(0.57-11.83)$ & 0.21 \\
\hline
\end{tabular}

Notes: $* P<0.05 ; * * P<0.01$.

Abbreviations: $\mathrm{OR}$, odds ratio; $\mathrm{Cl}$, confidence interval; $\mathrm{ASD}$, autism spectrum disorder. 
were more likely to be self-determined while engaging in "solitary/parallel leisure" and "social activities" than in other activities. However, Australian females displayed a weak relationship between self-determined motivation and solitary/ parallel leisure $(\mathrm{OR}=0.44,95 \% \mathrm{CI}=0.22-0.89)$. Regarding perceived difficulty, participants were more likely to report productive activities as difficult than other activities. Participants with higher levels of global social anxiety had stronger relationships between perceived difficulty and engagement in productive activities $(\mathrm{OR}=1.05,95 \% \mathrm{CI}=1.01-1.09)$ and social activities $(\mathrm{OR}=1.08,95 \% \mathrm{CI}=1.03-1.14)$.

\section{Relationships between motivation and perceived social reciprocity and types of social interaction}

Multilevel analyses in Table 3 showed that participants were more likely to be self-determined while interacting with family members and casual/intimate friends than with other social partners. Further, they were more likely to perceive higher levels of being listened to during interaction with casual/ intimate friends. Upon close inspection, global social anxiety moderated the relationship between thought of caring about others and interaction with casual/intimate friends $(\beta=-0.10$, standard error $=0.02, P<0.01)$. That is, participants with higher levels of global social anxiety were less likely to care about casual/intimate friends while interacting with them.

\section{Discussion}

We explored the motivation for social engagement in everyday contexts among cognitively able adolescents and adults with ASD through the lens of SDT, using ESM as a methodology. We investigated the controversy whether cognitively able adolescents and adults with ASD desire to engage socially. Three possible perspectives have been proposed: they prefer not to engage socially;, ${ }^{5,6}$ they wish to engage socially but express that desire more implicitly than explicitly; ${ }^{6,8,9}$ and the desire for social engagement is context specific as suggested by SDT. ${ }^{12-14}$ Our findings support the latter view.

In line with SDT, ${ }^{12,14}$ the results suggest that cognitively able adolescents and adults with ASD were motivated to interact in situations where they felt competent and experienced social reciprocity. Specifically, they were motivated to engage in social activities where they did not experience significant difficulty. Further, cognitively able adolescents and adults with ASD were motivated to interact with friends and perceived their friends as listening to them during interactions. These findings indicate that social activities and interactions with friends are the everyday contexts that support basic psychological needs and facilitate motivation for engagement. Consequently, they reported enjoying these social situations (Chen et al, unpublished data, 2015). Thus, our findings highlight the importance of context when exploring motivation for, and perceptions of, everyday social participation.

Perceiving the social contexts of interaction with friends as being listened to may reflect how cognitively able adolescents and adults with ASD characterize friendship. Our findings are similar to those of Howard et $\mathrm{al}^{44}$ who found that adolescents with ASD defined a friend as a person who provides care and responds to needs. These findings suggest

Table 3 Multilevel analyses of the self-determined motivation and perceptions of social reciprocity while interacting with different people

\begin{tabular}{|c|c|c|c|c|c|c|}
\hline \multirow[t]{3}{*}{ Variables } & \multirow{2}{*}{\multicolumn{2}{|c|}{$\begin{array}{l}\text { Multilevel logistic analysis } \\
(\mathrm{N}=30, \text { number of } \\
\text { surveys }=I, 13 \mathrm{I}) \\
\text { Self-determined motivation }\end{array}$}} & \multicolumn{4}{|c|}{$\begin{array}{l}\text { Multilevel linear analyses }^{a} \\
(\mathrm{~N}=27, \text { number of surveys }=316)\end{array}$} \\
\hline & & & \multicolumn{2}{|l|}{ Being listened to } & \multicolumn{2}{|c|}{ Caring about others } \\
\hline & OR (95\% CI) & $P$-value & Coefficient (SE) & $P$-value & Coefficient (SE) & $P$-value \\
\hline \multicolumn{7}{|l|}{ Level I } \\
\hline \multicolumn{7}{|l|}{ Social interaction situation } \\
\hline No one & $\mathrm{I} .89(0.95-3.8 \mathrm{I})$ & 0.71 & & & & \\
\hline With family members & $2.62(1.13-6.06)$ & $<0.05 *$ & $0.58(0.45)$ & 0.21 & $0.4 \mathrm{I}(0.47)$ & 0.38 \\
\hline With casual/intimate friends & $4.17(2.10-8.31)$ & $<0.01 * *$ & $1.24(0.36)$ & $<0.05^{*}$ & $0.69(0.37)$ & 0.06 \\
\hline With people at school/work & $1.17(0.54-2.53)$ & 0.70 & $0.56(0.4 I)$ & 0.18 & $0.05(0.43)$ & 0.91 \\
\hline \multicolumn{7}{|l|}{ Level 2} \\
\hline ASD severity & $1.05(0.96-1.15)$ & 0.32 & $0.04(0.06)$ & 0.47 & $0.78(0.66)$ & 0.25 \\
\hline Severity of global social anxiety & $0.96(0.92-1.01)$ & 0.09 & $-0.02(0.03)$ & 0.40 & $0.05(0.05)$ & 0.39 \\
\hline Australian females (vs others) & $0.38(0.11-1.29)$ & 0.12 & $0.48(0.73)$ & 0.52 & $-0.01(0.02)$ & 0.59 \\
\hline
\end{tabular}

Notes: ${ }^{a}$ Three Taiwanese male participants were excluded from the analyses as they did not interact with other people during the sampling period. $* P<0.05$; $* * P<0.01$. Abbreviations: $\mathrm{OR}$, odds ratio; $\mathrm{Cl}$, confidence interval; $\mathrm{ASD}$, autism spectrum disorder; SE, standard error. 
that, whereas children consider friendships in terms of companionship, ${ }^{45}$ adolescents and adults value the affective components of friendship.

In addition to the impact of context, our findings suggest that global social anxiety, an individual characteristic, influences perceptions of competence and social reciprocity in social interactions. Individuals with higher global social anxiety were more likely to perceive social activities as difficult than those with lower levels of social anxiety. This finding may suggest that cognitively able individuals with ASD who concurrently have social anxiety may be more self-aware of their social difficulties than those without social anxiety. ${ }^{46}$ The association between perception of difficulty in social activities and social anxiety may explain our previous finding of a negative relationship between time spent in social situations and severity of social anxiety (Chen et al, unpublished data, 2015).

In contrast to our current findings, other researchers ${ }^{15}$ have identified that adolescents with AS are not intrinsically motivated to develop friendships. In addition to the difference in methodology used, the discrepancy in the findings may be explained by the extent to which basic needs to feel competent and related are met at different stages of a social interaction. When our participants responded to a signal from the iOS device and indicated that they were already engaged in a social interaction with a trusted friend or partner - someone with whom the participant had already established a relationship. Other researchers, however, have described difficulty with the initiation of social interactions and establishing friendships, ${ }^{4}$ which may reflect a gap between social demands and their beliefs about their social skills. ${ }^{47,48}$ Conscious awareness of being "different" and fear of being "excluded" may contribute to reduced feelings of relatedness, ${ }^{4}$ which, in turn, may result in fewer attempts at initiating everyday social interactions. ${ }^{11,49,50}$ Presumably, friendships develop out of a motivation to engage with others; if motivation is low because of unmet basic needs, then friendships will not follow. However, clearly our participants managed to establish some valued friendships.

We did not find a significant relationship between interacting with friends and caring about what they were thinking or doing. This may reflect a core characteristic of ASD: a lack of social reciprocity. ${ }^{3}$ Deficits in understanding social or emotional cues of others and considering others' perspectives may influence willingness to care about others. ${ }^{51,52}$ Although our participants nominated friends, further research is required to investigate the meaning and true nature of their friendships.
Limitations in this study design require consideration when interpreting the findings. First, we did not recruit neurotypical adolescents and adults because the purpose of the study was to explore the motivation for social engagement and identify individual characteristics related to motivation and needs satisfaction among individuals with ASD. Thus, we do not know how the experiences of our participants compare with those of neurotypical adolescents and adults. Further, because of the relatively low incidence of cognitively able adolescents and adults with autism, our participants represented a wide age range. Therefore, the effect of differences in developmental stage on our findings is unknown. Further research in these areas is required. Second, due to different recruitment procedures, we were unable to match the number of males and females in Australia and Taiwan. We had more female participants in Australia, probably due to their interest and willingness to volunteer. ${ }^{16}$ Nonetheless, we did not find differences between groups as a function of nationality. Further, the results align with the findings of previous researchers. Finally, half of the participants from Australia and a quarter of those from Taiwan had comorbid mental health diagnoses. Because of the relatively small sample size, we were not able to take into account the effects of additional diagnoses or medications on social experience. Further research is needed to examine the effects of comorbidities and compare the findings with neurotypical adolescents and adults. While the application of multilevel analysis may offset the unequal numbers of male and female participants in the two countries, ${ }^{37}$ a larger sample size is required before the findings can be generalized.

\section{Conclusion}

Our findings highlight several important considerations for research and practice. Exploring in-the-moment experiences may provide contextually accurate and detailed information to facilitate intervention to enhance social participation of cognitively able adolescents and adults with ASD. Although our participants were motivated and did not perceive significant difficulty while being engaged socially, they still spent limited time in social situations. Researchers and professionals may need to consider ways to improve social skills and enhance perceived competence for initiating social interactions. Perceived challenges with initiating social interaction may be the result of previous experiences (eg, being excluded). Given that severity of social anxiety was often associated with perceptions of social engagement, strategies targeting social anxiety management should be incorporated into interventions. Because cognitively able 
adolescents and adults with ASD were motivated to interact with friends, service providers and researchers may need to consider incorporating peers in intervention and promoting friendship as an important intervention outcome.

\section{Acknowledgments}

The study was completed by the first author as part of the requirements for the completion of $\mathrm{PhD}$ under supervision of the second, third, and fifth authors. The authors would like to acknowledge the Faculty of Health Sciences, University of Sydney for the awarding of Mary Frances Stephens Scholarship and Postgraduate Research Support Scheme. This study was supported by National Science Council (NSC1022314-B-002-019) and National Taiwan University Hospital (NTUH101-M2004), Taiwan. The authors thank Prof Susan Shur-Fen Gau and Prof Shu-Hui Chen for their permission to use the Chinese version of Social Responsiveness Scale and the Social Interaction Anxiety Scale. The authors also thank the people who participated in the research, National Taiwan University Hospital, Autism Spectrum Australia (Aspect), and other autism related associations in Australia for assistance in research advertisement and recruitment. The authors are grateful to Ms Sarah Wilkes-Gillan for help with editing.

\section{Disclosure}

The authors report no conflicts of interest in this work.

\section{References}

1. Howlin P, Mawhood L, Rutter M. Autism and developmental receptive language disorder - a follow-up comparison in early adult life. II: Social, behavioural, and psychiatric outcomes. J Child Psychol Psychiatry. 2000;41(5):561-578.

2. Shattuck PT, Seltzer MM, Greenberg JS, et al. Change in autism symptoms and maladaptive behaviors in adolescents and adults with an autism spectrum disorder. J Autism Dev Disord. 2007;37(9):1735-1747.

3. American Psychiatric Association. Diagnostic and statistical manual of mental disorders. 4th ed. Washington, DC: American Psychiatric Association; 2000.

4. Müller E, Schuler A, Yates GB. Social challenges and supports from the perspective of individuals with Asperger syndrome and other autism spectrum disabilities. Autism. 2008;12(2):173-190.

5. Chevallier C, Kohls G, Troiani V, Brodkin ES, Schultz RT. The social motivation theory of autism. Trends Cogn Sci. 2012;16(4):231-239.

6. Deckers A, Roelofs J, Muris P, Rinck M. Desire for social interaction in children with autism spectrum disorders. Research in Autism Specttrum Disorders. 2014;8(4):449-453.

7. Voncken M, Rinck M, Deckers A, Lange WG. Anticipation of social interaction changes implicit approach-avoidance behavior of socially anxious individuals. Cognitive Ther Res. 2012;36(6):740-749.

8. Burnette CP, Henderson HA, Inge AP, Zahka NE, Schwartz CB, Mundy PC. Anterior EEG asymmetry and the modifier model of autism. J Autism Dev Disord. 2011;41(8):1113-1124.

9. Sutton SK, Burnette CP, Mundy PC, et al. Resting cortical brain activity and social behavior in higher functioning children with autism. J Child Psychol Psychiatry. 2005;46(2):211-222.
10. Davidson RJ. Anxiety and affective style: Role of prefrontal cortex and amygdala. Biol Psychiatry. 2002;51(1):68-80.

11. Hintzen A, Delespaul P, van Os J, Myin-Germeys I. Social needs in daily life in adults with pervasive developmental disorders. Psychiatry Res. 2010;179(1):75-80.

12. Deci EL, Ryan RM. The "what" and "why" of goal pursuits: Human needs and the self-determination of behavior. Psychological Inquiry. 2000;11(4):227-268.

13. Deci EL, Ryan RM. Self-determination theory: A macrotheory of human motivation, development, and health. Canadian Psychology. 2008;49(3):182-185.

14. Ryan RM, Deci EL. Self-determination theory and the facilitation of intrinsic motivation, social development, and well-being. Am Psychol. 2000;55(1):68-78.

15. Whitehouse AJO, Durkin K, Jaquet E, Ziatas K. Friendship, loneliness and depression in adolescents with Asperger's Syndrome. J Adolesc. 2009;32(2):309-322.

16. Hektner JM, Schmidt JA, Csikszentmihalyi M. Experience sampling method: Measuring the quality of everyday life. Thousand Oaks, CA: Sage Publications, Inc; 2007.

17. Csikszentmihalyi M, Larson RW. Being adolescent: Conflict and growth in the teenage years. New York: Basic Books; 1984.

18. Richard JF, Schneider BH. Assessing friendship motivation during preadolescence and early adolescence. Journal of Early Adolescence. 2005;25(3):367-385.

19. Shiffman S, Stone AA, Hufford MR. Ecological momentary assessment. Annu Rev Clin Psychol. 2008;4:1-32.

20. Tourangeau R. Remembering what happened: Memory errors and survey reports. In: Stone AA, Turkkan JS, Bachrach CA, Jobe JB, Kurtzman H.S, Cain VS, editors. The science of self-report: Implications for research and practice. Mahwah, NJ: Erlbaum; 1999:29-47.

21. Conner TS, Tennen H, Fleeson W, Barrett LF. Experience sampling methods: A modern idiographic approach to personality research. Soc Personal Psychol Compass. 2009;3(3):292-313.

22. Chen YW, Bundy A, Cordier R, Einfeld S. Feasibility and usability of experience sampling methodology for capturing everyday experiences of individuals with autism spectrum disorders. Disabil Health J. 2014;7(3):361-366.

23. Chen YW, Cordier R, Brown N. A preliminary study on the reliability and validity of using experience sampling method in children with autism spectrum disorders. Dev Neurorehabil. Epub 2015 Aug 24.

24. Khor AS, Gray KM, Reid SC, Melvin GA. Feasibility and validity of ecological momentary assessment in adolescents with high-functioning autism and Asperger's disorder. J Adolesc. 2014;37(1):37-46.

25. Cordier R, Brown N, Chen YW, Wilkes-Gillan S, Falkmer T. Piloting the use of experience sampling method to investigate the everyday social experiences of children with Asperger syndrome/high functioning autism. Dev Neurorehabil. Epub 2015 Aug 24.

26. Hare DJ, Wood C, Wastell S, Skirrow P. Anxiety in Asperger's syndrome: Assessment in real time. Autism. 2015;19(5):542-552.

27. American Psychiatric Association. Diagnostic and statistical manual of mental disorders. 5th ed. Washington, DC: American Psychiatric Association; 2013.

28. Woodcock RW. Woodcock Reading Mastery Tests, Third Edition (WRMT-III). San Antonio, TX Pearson Education, Inc.; 2011.

29. Wechsler D. WAIS-IV Administration and Scoring Manual. San Antonio, TX: The Psychological Corporation; 2008.

30. Myin-Germeys I, Nicolson NA, Delespaul PA. The context of delusional experiences in the daily life of patients with schizophrenia. Psychol Med. 2001;31(3):489-498.

31. The University of Sydney; 2012. Manual of PIEL Survey Application. [Mobile app]. Available from: http://pielsurvey.org/. Accessed January $20,2014$.

32. Constantino JN, Gruber CP. Social Responsiveness Scale, Second Edition (SRS-2). Torrance, CA: Western Psychological Services; 2012.

33. Gau SS, Liu LT, Wu YY, Chiu YN, Tsai WC. Psychometric properties of the Chinese version of the Social Responsiveness Scale. Research in Autism Spectrum Disorders. 2013;7(2):349-360. 
34. Bölte S. Brief Report: The Social Responsiveness Scale for Adults (SRS-A): Initial results in a German cohort. J Autism Dev Dis. 2012; 42(9):1998-1999.

35. Mattick RP, Clarke JC. Development and validation of measures of social phobia scrutiny fear and social interaction anxiety. Behav Res Ther. 1998;36(4):455-470.

36. Yang JF. The relations of social anxiety, Internet social anxiety and characteristics of the Internet [master's thesis]. Taiwan: Department of Psychology, National Taiwan University; 2003.

37. Hox J. Multilevel analysis: Techniques and applications. New York: Routledge; 2010.

38. Snijders TAB, Bosker RJ. Multilevel analysis: An introduction to basic and advanced multilevel modeling. London, UK: Sage Publications Ltd; 2012.

39. Schwartz JE, Stone AA. Strategies for analyzing ecological momentary assessment data. Health Psychol. 1998;17(1):6-16.

40. Fleeson W. Studying personality processes: Explaining change in between-persons longitudinal and within-person multilevel models. In: Robins RW, Fraley RC, Krueger RF, editors. Handbook of research methods in personality psychology. New York, NY: Guilford Press; 2007:523-542.

41. Scherbaum CA, Ferreter JM. Estimating statistical power and required sample sizes for organizational research using multilevel modeling. Organ Res Methods. 2009;12(2):347-367.

42. Maas CJ, Hox JJ. Robustness issues in multilevel regression analysis. Stat Neerl. 2004;58(2):127-137.

43. Raudenbush SW, Bryk A, Cheong YF, Congdon R, du Toit M. HLM 7: Hierarchical linear and nonlinear modeling. Lincolnwood, IL: Scientific Software International, Inc; 2011.
44. Howard B, Cohn E, Orsmond G. Understanding and negotiating friendships: Perspectives from an adolescent with Asperger syndrome. Autism. 2006;10(6):619-627.

45. Calder L, Hill V, Pellicano E. 'Sometimes I want to play by myself': Understanding what friendship means to children with autism in mainstream primary schools. Autism. 2013;17(3):296-316.

46. Mazurek MO, Kanne SM. Friendship and internalizing symptoms among children and adolescents with ASD. J Autism Dev Disord. 2010; 40(12):1512-1520.

47. Capps L, Sigman M, Yirmiya N. Self-competence and emotional understanding in high-functioning children with autism. Dev Psychopathol. 1995;7(1):137-149.

48. Vickerstaff S, Heriot S, Wong M, Lopes A, Dossetor D. Intellectual ability, self-perceived social competence, and depressive symptomatology in children with high-functioning autistic spectrum disorders. J Autism Dev Dis. 2007;37(9):1647-1664.

49. Orsmond GI, Kuo HY. The daily lives of adolescents with an autism spectrum disorder. Autism. 2011;15(5):579-599.

50. Shattuck PT, Orsmond GI, Wagner M, Cooper BP. Participation in social activities among adolescents with an autism spectrum disorder. PloS One. 2011;6(11):e27176.

51. Baron-Cohen S. The autistic child's theory of mind: A case of specific developmental delay. J Child Psychol Psychiatry. 1989;30(2):285-297.

52. Baron-Cohen S, Jolliffe T, Mortimore C, Robertson M. Another advanced test of theory of mind: Evidence from very high functioning adults with autism or Asperger syndrome. J Child Psychol Psychiatry. 1997;38(7):813-822.
Neuropsychiatric Disease and Treatment

\section{Publish your work in this journal}

Neuropsychiatric Disease and Treatment is an international, peerreviewed journal of clinical therapeutics and pharmacology focusing on concise rapid reporting of clinical or pre-clinical studies on a range of neuropsychiatric and neurological disorders. This journal is indexed on PubMed Central, the 'PsycINFO' database and CAS,

\section{Dovepress}

and is the official journal of The International Neuropsychiatric Association (INA). The manuscript management system is completely online and includes a very quick and fair peer-review system, which is all easy to use. Visit http://www.dovepress.com/testimonials.php to read real quotes from published authors. 